\title{
Experimental investigation of liquid film cooling in hypersonic flow
}

Cite as: Phys. Fluids 31, 046101 (2019); https://doi.org/10.1063/1.5088024

Submitted: 07 January 2019 . Accepted: 11 March 2019 . Published Online: 02 April 2019

Chaokai Yuan (苑朝凯) (D), Jinping Li (李进平) (D), Zonglin Jiang (姜宗林), and Hongru Yu (㓩鸿儒)

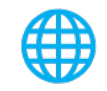

\section{ARTICLES YOU MAY BE INTERESTED IN}

High-enthalpy models for boundary-layer stability and transition

Physics of Fluids 31, 044101 (2019); https://doi.org/10.1063/1.5084235

Numerical study of the shear-thinning effect on the interaction between a normal shock wave and a cylindrical liquid column

Physics of Fluids 31, 043101 (2019); https://doi.org/10.1063/1.5083633

Wave profile along a ship hull, short farfield waves, and broad inner Kelvin wake sans divergent waves

Physics of Fluids 31, 047102 (2019); https://doi.org/10.1063/1.5088531

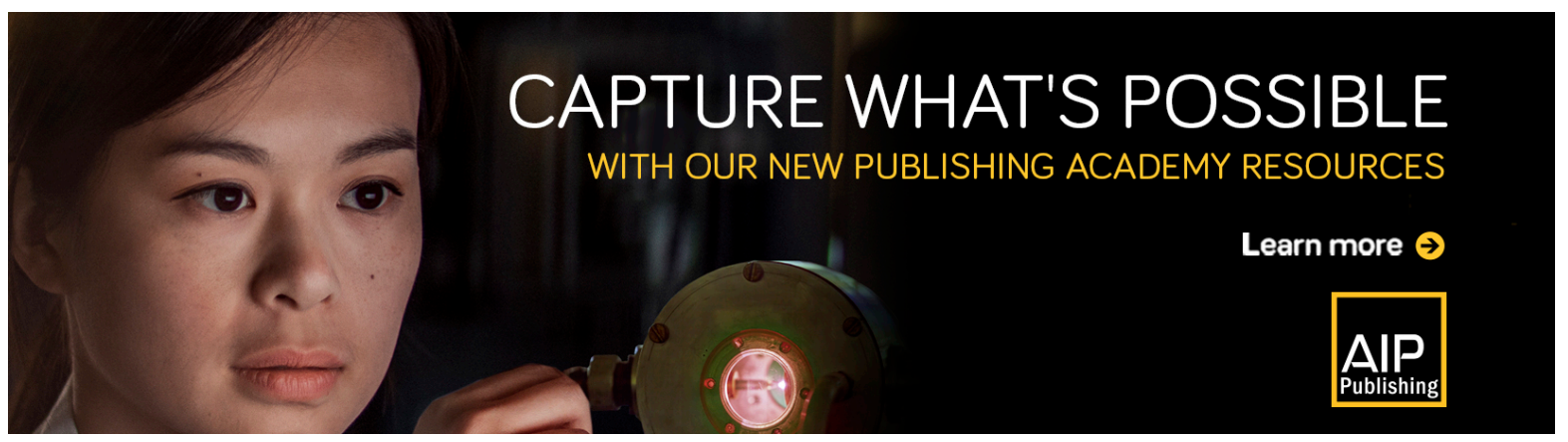




\title{
Experimental investigation of liquid film cooling in hypersonic flow
}

\author{
Cite as: Phys. Fluids 31, 046101 (2019); doi: 10.1063/1.5088024 \\ Submitted: 7 January 2019 • Accepted: 11 March 2019 • \\ Published Online: 2 April 2019
}

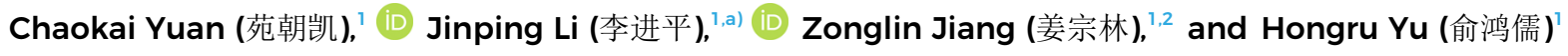

\begin{abstract}
AFFILIATIONS
${ }^{1}$ State Key Laboratory of High-temperature Gas Dynamic, Institute of Mechanics, Chinese Academy of Sciences, Beijing 100190, China

${ }^{2}$ School of Engineering Sciences, University of Chinese Academy of Sciences, Beijing 100049, China
\end{abstract}

a)lijinping@imech.ac.cn

\begin{abstract}
Film cooling is generally considered as a promising active cooling technology for developing thermal protection systems of hypersonic vehicles; however, most of experimental and numerical studies of film cooling mainly concentrated on gaseous film cooling. Since the phase change of liquid coolants can absorb a large amount of latent heat, liquid film cooling should have more potential advantages, especially for severe environments accompanied by hypersonic flight. To address this issue, the film cooling using water as a coolant was experimentally investigated in hypersonic flow. Experiments were carried out in a detonation tunnel, at a hypersonic Mach number of 6 using a $25^{\circ}$ apex-angle wedge. Characteristic physical quantities, such as surface temperature rise, shock wave structure, film thickness, and cover area, are measured by thermocouples, schlieren, and a specially devised liquid film measurement system. The experimental results verify that the liquid film cooling is feasible in hypersonic flow and also indicate that it is featured with maintaining aerodynamic performances due to the weak effect on the main flow caused by coolant injection. Inspired by these results, liquid film flow characteristics and its influencing factors including mass flow rate, dynamic pressure, coolant injection direction, and surface tension are investigated to guide the design of a thermal protection system.
\end{abstract}

Published under license by AIP Publishing. https://doi.org/10.1063/1.5088024

\section{INTRODUCTION}

Hypersonic vehicles encounter severe aerodynamic heating during flight. High levels of aerodynamic heating can cause malfunction or even damage to delicate on-board electronic devices. ${ }^{1}$ For such reasons, a thermal protection system (TPS) is always needed and becomes a key issue driving the design of hypersonic vehicles. Over the years, passive and semipassive thermal protection systems, including insulated structure, heat sink, hot structure, heat pipe, and ablation, ${ }^{2}$ have become relatively mature. This promoted the development of rocket-powered space vehicles, re-entry vehicles, and ballistic missiles. Currently, thinner sharp edges and sharper noses have been adopted to improve the aerodynamic performance in the design of interceptor missiles, hypersonic cruise aircraft, and space-access vehicles powered by airbreathing engines. One of the challenges for such vehicles is to balance the desire for high aerodynamic performance with the increased aerodynamic heating to the airframe. Small diameters of the vehicle nose and leading edge can dramatically increase the heat fluxes on vehicle surfaces. ${ }^{3}$ For example, the heat flux on the leading edge of a scramjet engine with a Mach number of 10 can achieve $1053 \mathrm{MW} / \mathrm{m}^{2}$, while at the stagnation point of the nose cap, the heat flux can exceed $1400 \mathrm{MW} / \mathrm{m}^{2}$. If a leading edge is designed with a radius of $10 \mathrm{~mm}$ to improve the aerodynamic efficiency, the maximum temperature of such an uncooled structure during flight will exceed $5000^{\circ} \mathrm{C} .{ }^{4}$ Such an extremely high temperature environment exceeds the thermomechanical limits of available materials, and active cooling systems should be considered for thermal management. ${ }^{5,6}$ Many active cooling techniques have been proposed and studied, including forward-facing cavity, opposing jet, ${ }^{8}$ aerospike, ${ }^{9}$ film cooling, and transpiration cooling. According to comparisons between different active techniques, transpiration cooling and film cooling are the promising technologies for thermal management of hypersonic vehicles. ${ }^{1,10}$ Transpiration cooling has been widely researched using both gaseous and liquid coolants, and experimental studies have predicted that the cooling effectiveness using liquid coolants is much higher than that using 
gaseous coolants. ${ }^{11}$ However, the porous material in transpiration cooling remains a challenging research problem. The reason is that in addition to the aerodynamic heating, the TPS must be able to withstand aerodynamic loads and should also have similar thermal expansion and strain coefficients as the underlying structure. ${ }^{12}$ To date, it has been difficult for the porous material to meet all the requirements. Film cooling ejects cooling air through the slots to the external surface of the vehicle. A thin layer film is then established on the surface, isolating the outer main flow from the wall and reducing the heat flux. ${ }^{13}$ Film cooling is free of the above problems for the slots manufactured with the same material as the aircraft. However, early experimental and numerical studies of film cooling mainly concentrated on gaseous film cooling ${ }^{14-16}$ and few studies on liquid film cooling in hypersonic flow were published. Considering the high cooling efficiency of liquid coolants, we sought to investigate hypersonic liquid film cooling.

The main objectives of the present study are (1) to verify whether a liquid film can be formed in the hypersonic flow field and effectively isolate the external high temperature flow, (2) to confirm the effect of the liquid film on the flowfield, (3) to visualize the liquid film and develop a method to measure the liquid film thickness, and (4) to investigate the liquid film flow characteristics and their influencing factors in hypersonic flow which will guide the design of thermal protection systems. The details of this study are discussed in Secs. II and III.

\section{EXPERIMENTAL APPARATUS}

\section{A. Wind tunnel}

The facility employed for the experiments is a detonation wind tunnel, schematically shown in Fig. 1. It mainly consists of four parts. From left to right, the first part is the damping section that is $3 \mathrm{~m}$ in length. The function of this part is to reduce structural strength requirement and increase test time. Next to the damping section is the detonation section that is $28 \mathrm{~m}$ in length. The inner diameters of the two sections are $224 \mathrm{~mm}$. The contoured nozzle is $2 \mathrm{~m}$ in length, and its exit diameter is $300 \mathrm{~mm}$. The last part is the test and vacuum section, which is $10 \mathrm{~m}$ in length and $1220 \mathrm{~mm}$ in diameter. The damping section, detonation section, and nozzle were separated by a diaphragm as shown in Fig. 1. An igniter is installed at the right end of the detonation tube to initiate directly backward-running detonation. The explosive mixture in the detonation section is hydrogen, oxygen, and nitrogen, and the molar ratio is based on the experimental situation. The test gas is the burning gas after detonation. The detonation wind tunnel can generate a relatively high enthalpy flow field with limited test time. To prolong the test time to $100 \mathrm{~ms}$, the facility can also be operated as a conventional wind tunnel, with decreased enthalpy of the test flow. In this operation mode, high pressure air was filled in the interconnected damping section and detonation section.

\section{B. Test model}

In the present investigation, the test model is a $25^{\circ}$ apex-angle wedge with a width of $150 \mathrm{~mm}$ and a length in the streamwise direction of $200 \mathrm{~mm}$, as shown in Fig. 2(a). The convective surface heat-transfer rates and liquid film thickness are simultaneously measured using coaxial thermocouples and coaxial conductivity probes, respectively. Limited by the internal space of the test model, the injection slot is $75 \mathrm{~mm}$ from the leading edge of the model. The configuration of the injection slot and sensors on the upper surface of the model is shown in Fig. 2(b). The injection slot is replaceable in order to change the angle between model surface normals and the coolant injection direction (labelled $\theta$ ). In our experiments, three configurations of the injection slot were used, as shown in Fig. 3.

\section{Coolant supply system}

Water is an attractive coolant because it has an extremely high heat of vaporization. ${ }^{17}$ Therefore, in this study, tap water is selected for the coolant and is injected into the hypersonic flow through a $20 * 0.2 \mathrm{~mm}$ slot at the model upper surface. A flexible pipe connected to this slot passes internally through the model and support system to the external coolant supply system. The coolant supply system contains coolant water in a cylinder tank, and the outlet mass flow rate is controlled by a pressure regulator. Additionally, to control the coolant injection time, an electromagnetic valve is installed close to the slot. The opening time of the valve is calibrated before experiments to ensure that water is injected after a hypersonic flow field is established.

\section{Liquid film thickness measurement}

For liquid film cooling, film thickness is one of the most basic parameters. An accurate measurement of the liquid film thickness will be helpful to reveal the film formation conditions, promote cooling mechanism research, and evaluate cooling performance reasonably. However, there are few references regarding liquid film thickness measurement in hypersonic flow. In the area of two-phase flow, the development of methods to measure the liquid film thickness has been an important topic and many techniques based on acoustics, optics, and electronics have been proposed. ${ }^{18}$ However, all of the techniques have been developed with specific experimental conditions in mind and are not suitable as general methods. The flow field around a hypersonic vehicle is not uniform due to the presence of shock waves. This means that the distribution of sound velocity and refractive index varies, which will restrict the application of many methods. A detailed analysis shows that a conductance method appears to be the only candidate practicable in hypersonic flow. The measurement principle is based on the theory of electric field. ${ }^{19}$ As tap water is selected as a coolant, the liquid film is electrically conducting. The external flow field is air, and except for

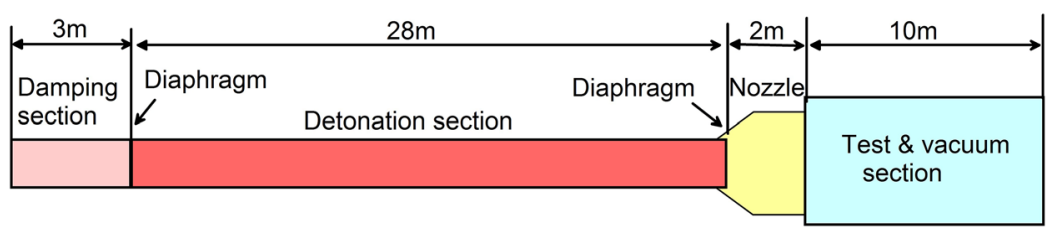

FIG. 1. Schematic diagram of the detonation wind tunnel. 


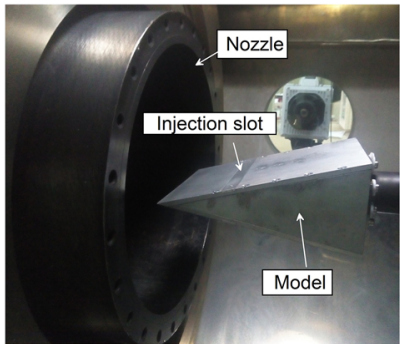

(a)

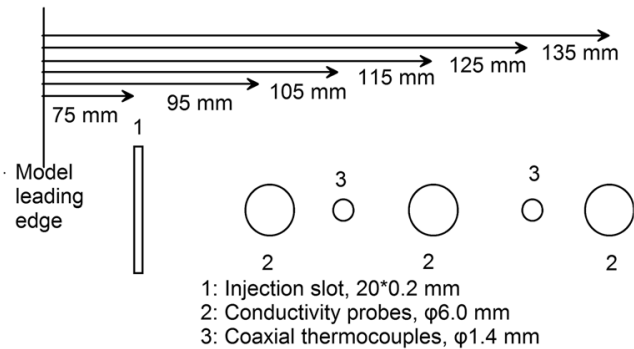

(b)

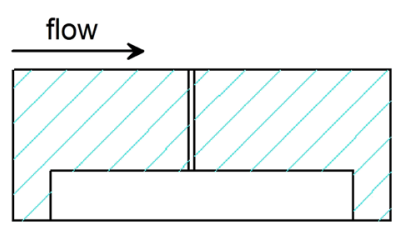

(a)

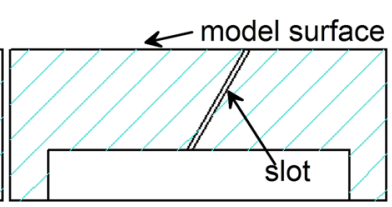

(b)

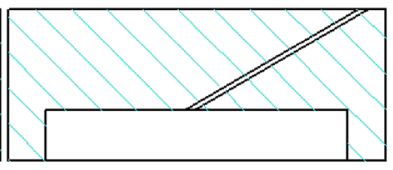

(c)
FIG. 2. (a) Photograph of a $25^{\circ}$ apex-angle wedge model. (b) Injection slot and sensor configuration on the model upper surface.

an extremely high flow velocity, the flow field is insulative. In this way, film thickness can be obtained by measuring the conductance between the two electrodes of the probe. Meanwhile, liquid film leading edge velocity can also be obtained by measuring the arrival time.

The coaxial conductivity probe and typical experimental arrangement are shown in Fig. 4. The probe consists of a transmitter electrode, an insulating layer, and a receiver electrode. The outer diameters of the transmitter electrode, insulating layer, and receiver electrode are 1.0, 5.0, and $6.0 \mathrm{~mm}$, respectively. The material of the electrode is copper, and the insulating layer is made of polyamide. For the probes that are flush-mounted on the model surface, the measurement is essentially nonintrusive.

In this paper, a liquid film thickness measurement system is first developed. It consists of an excitation source, a measurement unit, a reference unit, a differential amplification unit, and a data acquisition and processing unit. The liquid film thickness can be obtained from the output voltage as

$$
h=C \frac{V_{e}}{V_{o}},
$$

where $\mathrm{h}, \mathrm{V}_{e}, \mathrm{~V}_{o}$, and $\mathrm{C}$ represent the liquid film thickness, exciting signal amplitude, measured output signal amplitude, and system response characteristics, respectively. $\mathrm{V}_{e}$ is set in advance. To ascertain the system response characteristics, calibration is

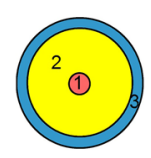

1 Transmitter electrode

2 Insulating layer 3 Receiver electrode

Probe

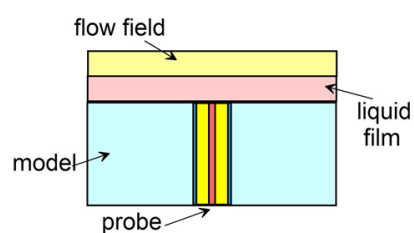

FIG. 4. Schematic diagram of the coaxial conductivity probe and typical experimental arrangement. needed prior to the measurements to relate the signal amplitude to thickness. The probe is immersed in water between the gap of two plates made of nonconductive material. The upper plate can move vertically up and down by micrometer screws with a step accuracy of $0.01 \mathrm{~mm}$. Figure 5 shows the measured system characteristics.

To eliminate the effects of changes in tap water quality, conductivity of the tap water used in probe calibration was also measured with a conductivity meter (FE38, METTLER TOLEDO). In each experiment, we measure the conductivity of the tap water injected into the coolant supply system and recalibrate the probe if there is a deviation.

\section{E. Flow visualization system}

The flow visualization system consists of two parts: a highspeed imaging system and a schlieren. High-speed imaging is carried out with a SA4 camera that takes photographs from the top optical window of the test section. A high-power light-emitting diode (LED)

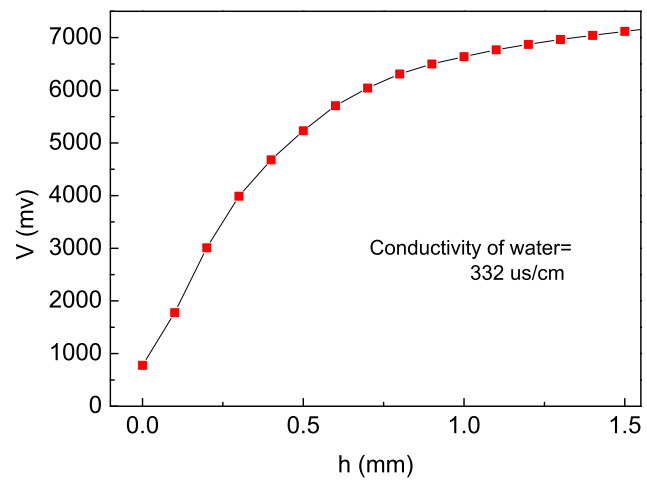

FIG. 5. Measured system response characteristics. 


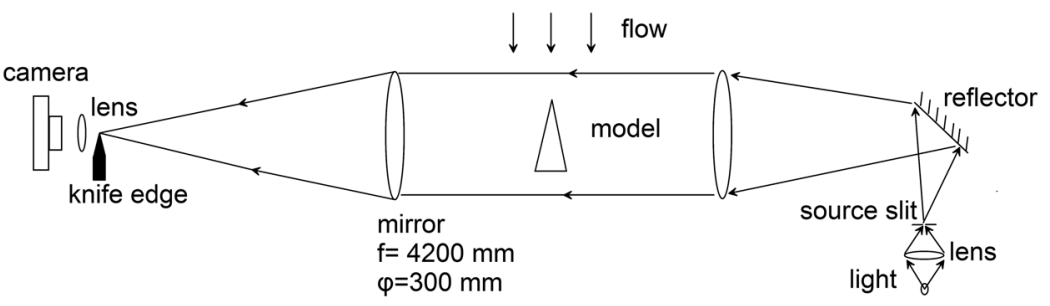

FIG. 6. Schematic diagram of the schlieren.

lamp is used to illuminate the model. The camera exposure time is set to $1 / 6000 \mathrm{~s}$, and the imaging frame rate is $3600 \mathrm{fps}$.

The effects of the liquid film on the shock wave position are investigated with the help of schlieren, schematically shown in Fig. 6. It mainly includes a light source coupled with a slit, two schlieren mirrors, reflector, lens, knife edge, and high-speed camera. The light source is a high-intensity xenon lamp in continuous mode. The displacement accuracy and moving range of the slit are $0.01 \mathrm{~mm}$ and $1.0 \mathrm{~mm}$, respectively. In the optical setup, two spherical mirrors with a diameter of $300 \mathrm{~mm}$ and a focal length of $4200 \mathrm{~mm}$ are used to collimate the light through the test section and focus it onto the knife edge. The knife edge at the focal point of the second schlieren mirror is oriented horizontally to obtain vertical density gradients and moving it to the optical axis makes the system more sensitive. Dynamic schlieren images are taken by a Photron SA 1.1 high-speed camera. The image resolution, frame rate, and exposure time of this high speed camera are $1024 * 1024$ pixels, $5400 \mathrm{fps}$, and 1/20 $000 \mathrm{~s}$, respectively.

\section{RESULTS AND DISCUSSION}

\section{A. Feasibility verification of liquid film cooling}

Formation of a liquid film and an effective reduction in surface heat flux are the primary foundations of liquid film cooling. Therefore, wind tunnel experiments were carried out to verify the feasibility of liquid film cooling. The initial fill conditions and free stream parameters are given in Table I. Typical stagnation pressure history measured at the nozzle entrance is shown in Fig. 7. It can be observable that the pressure behind the sharp jump keeps an acceptable constant value for approximately $30 \mathrm{~ms}$, which means that the uniform test duration is approximately $30 \mathrm{~ms}$.

TABLE I. Initial fill conditions and free stream parameters.

Fill conditions

Detonation section (bar)

Mixture molar ratio

Damping section $(\mathrm{Pa})$

Free stream parameters

Stagnation temperature (K)

Stagnation pressure (bar)

Static temperature $(\mathrm{K})$

Static pressure $(\mathrm{Pa})$

Dynamic pressure $(\mathrm{Pa})$

Mach number

Unit Reynolds number ( $1 / \mathrm{m})$
1.2

$\mathrm{H}_{2}: \mathrm{O}_{2}: \mathrm{N}_{2}=2: 1: 1.25$ 10 , air

2832

6.2

401

255

6432

6.0

$2.3 \times 10^{5}$
Figure 8, taken by the high-speed camera, shows a liquid film formed on the model surface approximately $29 \mathrm{~ms}$ after the flow field was established. The free stream flow is from left to right in Fig. 8, and the coolant mass flow rate is 10.6 grams per second $(\mathrm{g} / \mathrm{s})$. It can be seen that a liquid film can indeed form on the model surface. The black line in Fig. 8, added after experiments, shows the boundary of the liquid film coverage area. The coolant supply system is equipped with a fast response valve, but it still takes a while to fully open. Therefore, the distribution of mass flow rate along the slot is uneven at the beginning, which leads to the many small branches shown in Fig. 8.

To confirm the ability of the liquid film to isolate external high temperature airflow, surface temperature is measured using coaxial thermocouples with and without coolant injection. All experiments were carried out under the same conditions as those listed in Table I. The temperatures of the wedge surface and injected tap water are

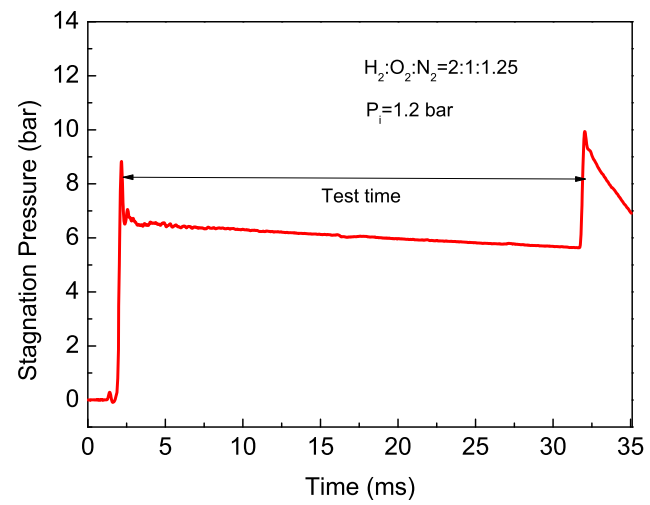

FIG. 7. Typical stagnation pressure signal.

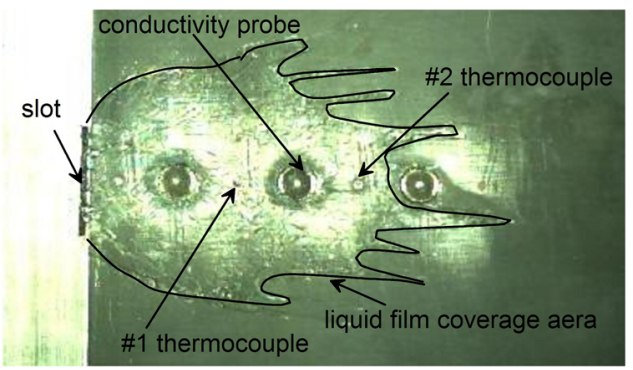

FIG. 8. Liquid film formed on the model surface with the black line indicating the liquid film boundary. 


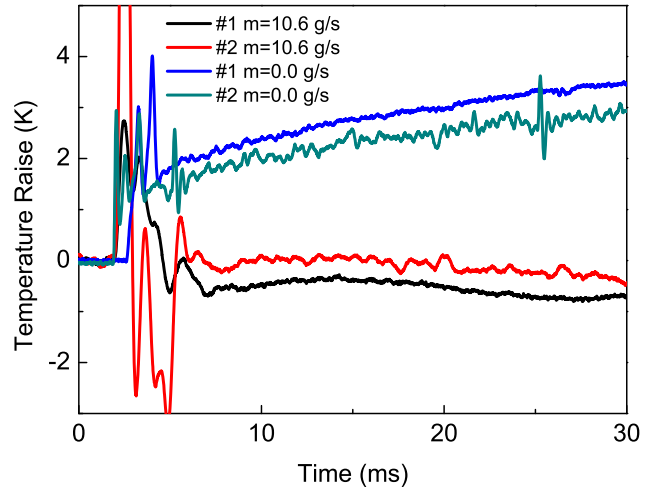

FIG. 9. Temperature-time histories from coaxial thermocouples with and without coolant injection.

both room temperature, namely, $296 \mathrm{~K}$. Typical temperature-time histories recorded from the coaxial thermocouples are shown in Fig. 9. The two thermocouples are labelled $\# 1$ and \#2, with distances to the model leading edge of $105 \mathrm{~mm}$ and $125 \mathrm{~mm}$, respectively. For the case without coolant, the measured temperature increases within test time are $3.5 \mathrm{~K}$ and $3.0 \mathrm{~K}$, respectively. The higher temperature increase in thermocouple \#1 is consistent with aerodynamic thermal theory. ${ }^{20,21}$ On the other hand, there is no apparent temperature increase in test time with coolant injection. By comparison, it can be determined that the liquid film can effectively isolate the external high temperature airflow and reduce the surface heat flux. With the liquid film, the measured temperature is slightly lower than the temperature before the flow field was established. The reason is that water temperature will decrease when injected into the vacuum environment. A similar phenomenon was reported in Ref. 4, which investigated transpiration cooling.

The above results show that liquid film cooling can be used in hypersonic thermal protection systems.

\section{B. Effect of coolant injection on flow field}

To investigate the influence of coolant injection on the flow field, schlieren was used to measure the shock angle. Experiments were conducted with coolant mass flow rates of $0.0,10.6$, and
$12.4 \mathrm{~g} / \mathrm{s}$. A MATLAB image processing algorithm was developed to extract the shock wave and model surface positions. Typical schlieren image and data extraction results are shown in Fig. 10. The shock angle was determined by the following steps: (1) measure the model upper surface inclination using a digital inclinometer; (2) extract the shock wave and model surface positions. (3) linearly fit the data to determine the included angle; (4) shock wave angle equals the sum of inclination and included angles. In the three experiments, the obtained model surface positions do not coincide with each other. The reason is that the high-speed camera was fixed by a tripod and was not carefully installed in an absolute horizontal plane. However, this had no effect on the final results using the above process to find shock angles.

With a coolant mass flow rate of $10.6 \mathrm{~g} / \mathrm{s}$, the shock angle increased from $25.8^{\circ}$ to $26.6^{\circ}$ compared with the absence of liquid film. By further increasing the mass flow rate to $12.4 \mathrm{~g} / \mathrm{s}$, the angle increased only by $0.1^{\circ}$. This indicates that liquid film cooling has a negligible effect on the position of the shock wave, which equates to less effect on aerodynamic performances. This is very advantageous for aircraft design. On the negative side, the liquid film will inevitably modify the boundary layer characteristics and may promote transition. But some research results show that, under certain conditions, surface cooling leads to flow stabilization and shifts the transition down-stream. ${ }^{22}$ It is worthwhile to study the combined effect, which is planned for the future.

\section{Liquid film flow characteristics and influencing factors}

Further experiments were carried out to study the flow characteristics and influencing factors of the liquid film under hypersonic flow, which are of great significance for engineering applications. The results can be used to guide the design of the injection slot and optimize system cooling efficiency. To prolong the test time to $100 \mathrm{~ms}$, high pressure air instead of burned gas was used as test gas. To prolong the test time, the wind tunnel was operated in conventional mode. The details of the test conditions for this set of experiments are summarized in Table II.

\section{Flow characteristics}

First, the liquid film flow process was measured. The flow field dynamic pressure and coolant mass flow rate were $9576 \mathrm{~Pa}$ and

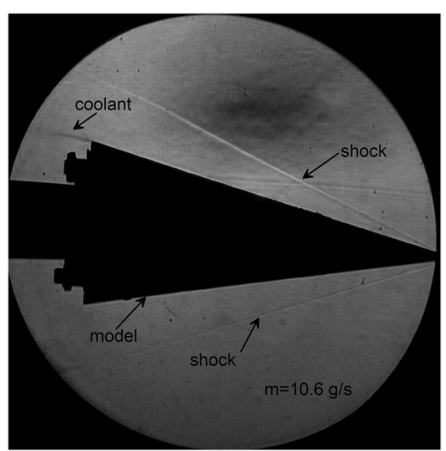

(a)

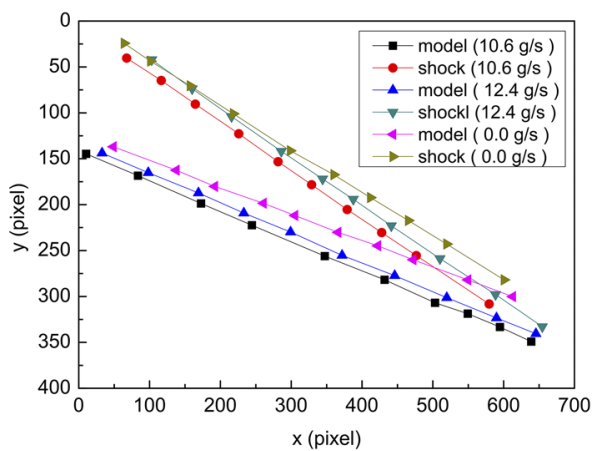

(b)
FIG. 10. (a) Typical schlieren image and (b) position extraction results. 
TABLE II. Test conditions for the current experiments.

\begin{tabular}{lccccc}
\hline \hline $\operatorname{Re}(1 / \mathrm{m})$ & $\mathrm{Ma}$ & $\mathrm{q}(\mathrm{Pa})$ & $\mathrm{m}(\mathrm{g} / \mathrm{s})$ & Injection direction $(\mathrm{deg})$ & Coolant \\
\hline $1.2 \times 10^{7}$ & 6.0 & 9576 & 7.1 & 0 & Tap water \\
$1.2 \times 10^{7}$ & 6.0 & 9576 & 10.6 & 0 & Tap water \\
$1.2 \times 10^{7}$ & 6.0 & 9576 & 12.4 & 0 & Tap water \\
$8.0 \times 10^{6}$ & 6.0 & 6397 & 7.1 & 0 & Tap water \\
$1.0 \times 10^{7}$ & 6.0 & 8000 & 7.1 & 0 & Tap water \\
$1.2 \times 10^{7}$ & 6.0 & 9576 & 10.6 & 30 & Tap water \\
$1.2 \times 10^{7}$ & 6.0 & 9576 & 10.6 & 60 & Tap water \\
$1.2 \times 10^{7}$ & 6.0 & 9576 & 10.6 & 60 & Tap water with washing powder \\
\hline \hline
\end{tabular}

$10.6 \mathrm{~g} / \mathrm{s}$, respectively. The liquid film thickness shown in Fig. 11 was measured by homemade coaxial conductivity probes. The probes labelled \#1, \#2, and \#3 were $95 \mathrm{~mm}, 115 \mathrm{~mm}$, and $135 \mathrm{~mm}$ from the model leading edge, respectively.

The analysis of the results is as follows: (1) The liquid film arrived at the three conductivity probes at $2.9 \mathrm{~ms}, 20.9 \mathrm{~ms}$, and $49.3 \mathrm{~ms}$, and the corresponding average speeds were $1.11 \mathrm{~m} / \mathrm{s}$ and $0.70 \mathrm{~m} / \mathrm{s}$, respectively. This indicates that the liquid film flow on the wedge surface decelerates gradually. This conclusion can also be proven by the increasing rise time of the three probes which implies local velocity. If the velocity at conductivity probes $\# 1$ and $\# 2$ are 1.11 and $0.7 \mathrm{~m} / \mathrm{s}$, respectively, the negative acceleration is $8 \mathrm{~m} / \mathrm{s}^{2}$, which is much larger than the acceleration due to gravity. Therefore, aerodynamic drag dominates the liquid film flow process. (2) Surface waves exist in the liquid film and evolve in time and space, which leads to a slight perturbation of liquid film thickness. The average thickness of the liquid film measured by conductivity probe \#1 was $0.23 \mathrm{~mm}$, and the standard deviation was $0.016 \mathrm{~mm}$. (3) Figure 12, taken by a high-speed camera, shows the liquid film formed on the model surface and the extracted liquid film width. The location of the injection slot center is set as the starting point of the $\mathrm{x}$ axis. Here, we find that lateral broadening occurs in the liquid film layer, that is, the width of the liquid film is greater than the injection slot width. The liquid film coverage area width increases sharply in the first few millimetres and then the growth rate decreases gradually. The reason is that the liquid film layer does not match with the flow field boundary

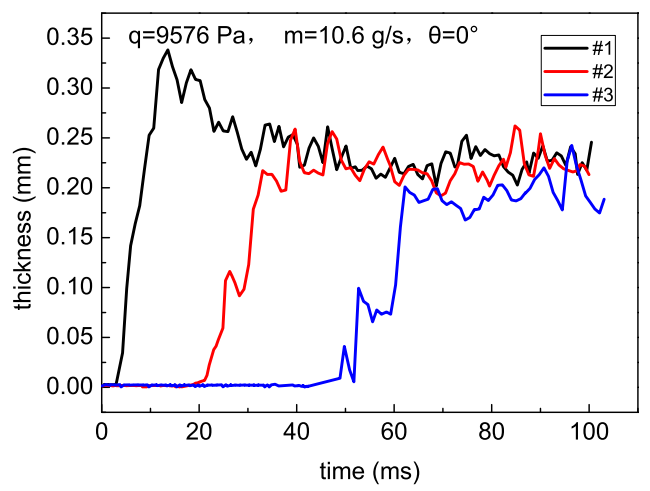

FIG. 11. Liquid film thickness measurement results. condition. After injection, a local protrusion is formed around the slot. A gradient exists that forces the coolant to flow to low-pressure areas, thus broadening the liquid film width. As the liquid film thickness decreases rapidly, the pressure gradient and the resulting lateral broadening effect decline.

\section{Mass flow rate}

The mass flow rate was altered to investigate its effect on liquid film flow characteristics. The coolant mass flow rate was set to 7.1 and $12.4 \mathrm{~g} / \mathrm{s}$. The measured liquid film thicknesses are shown in Figs. 13(a) and 13(b). Additionally, photographs taken by the high-speed camera were further analysed to obtain the liquid film distribution. The results are shown in Fig. 13(c). A comparison clarifies the following points: (1) The increasing time interval between the signal rise edges of conductivity probes indicates that liquid film flow on the model surface is a decelerating process, which is consistent with the above conclusions. (2) By increasing the coolant mass flow rate, the thickness of the liquid film does not obviously change. Taking the probe \#1 measurement results as an example, with coolant mass flow rates of $7.1,10.6$, and $12.4 \mathrm{~g} / \mathrm{s}$, average thicknesses of the liquid film during the test time were $0.215,0.232$, and $0.214 \mathrm{~mm}$, respectively. This difference failed to achieve statistical significance. The following experiments show that liquid film thickness is determined by flow dynamic pressure. Experimental results will be introduced in Sec. III C 3. (3) The coolant mass flow rate mainly affects the liquid film leading edge velocity and film width. A higher coolant mass flow rate will increase the liquid film leading edge velocity and film width. By increasing the coolant mass flow rate from 7.1 to $12.4 \mathrm{~g} / \mathrm{s}$, the initial outlet velocity at the injection slot increases 1.75 times. With the same mass flow rates, the measured time interval for the liquid film completely covering conductivity probes \#1 and \#3 are 69.86 and $23.82 \mathrm{~ms}$, and the corresponding average speeds are 0.57 and $1.68 \mathrm{~m} / \mathrm{s}$. The average velocity increases 2.93 times, which is much higher than the velocity increase due to increasing mass flow rate. The reason is that a protrusion formed around the injection slot after injection and did not match the flow boundary condition. This decelerates the test gas, while increasing the liquid film speed. Increasing the mass flow rate, this effect will be strengthened because the height of the protrusion will be increased. Additionally, it will broaden the liquid film coverage region. As shown in Fig. 13(c), increasing the mass flow rate from $7.1 \mathrm{~g} / \mathrm{s}$ to $12.4 \mathrm{~g} / \mathrm{s}$, the liquid film width increases approximately 1.7 times. 


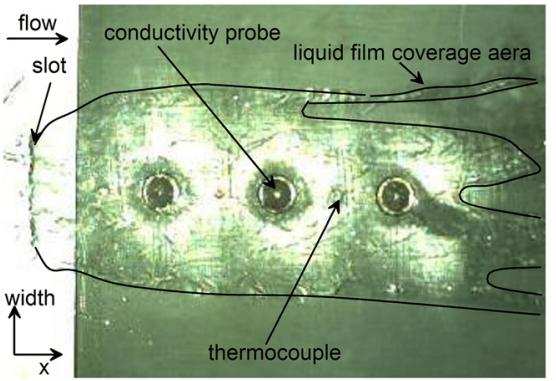

(a)

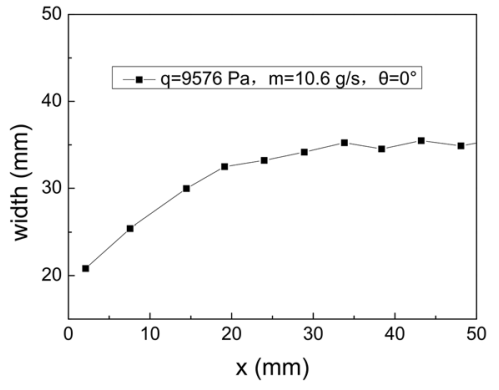

(b)
FIG. 12. (a) Liquid film formed on the model surface with the black line indicating the liquid film boundary and (b) extracted film coverage area width.

\section{Dynamic pressure}

Dynamic pressure is one of the most important parameters in the hypersonic vehicle design. Because it varies with flight altitude and velocity, it is necessary to carry out experiments to reveal its effect on liquid film flow characteristics. In this set of experiments, the coolant mass flow rate was set to $7.1 \mathrm{~g} / \mathrm{s}$ and the flow field dynamic pressures were 6397, 8000, and $9576 \mathrm{~Pa}$, respectively. The measured liquid film thickness is shown in Fig. 14.

In Figs. 14(a) and 14(b), only partial conductivity probe signals are given. The reason is that the liquid film does not cover all the conductivity probes during experimental time. When the flow dynamic pressure was $6397 \mathrm{~Pa}$, only the first conductivity probe was covered. Increasing flow dynamic pressure to $9567 \mathrm{~Pa}$, liquid film flows across all the three probes. This shows that flow dynamic pressure increases liquid film velocity. This places liquid film cooling in a favorable position for hypersonic thermal protection design. High dynamic pressure often means that aerodynamic heating of the flow field is more serious. ${ }^{20}$ Rapid establishment of the liquid film will reduce the start-up time of the cooling system, which equates to protecting hypersonic vehicles in a timely manner. Further analysis of the probe \#1 measurement results from 40 to $60 \mathrm{~ms}$ was conducted to obtain average film thickness. The reason is that probe \# 1 was the only probe that had results under three test conditions, and the liquid film thickness was relatively smooth during this period. With dynamic pressures of 6397, 8000, and $9576 \mathrm{~Pa}$, the measured liquid film thicknesses were $0.36,0.23$, and $0.21 \mathrm{~mm}$, respectively. This demonstrates clearly that increasing dynamic pressure will decrease the film thickness.

\section{Coolant injection direction}

The effects of the coolant injection direction on the liquid film flow characteristics were also identified. Here, we define the angle between model surface normals and the coolant injection direction as $\theta$. In this series of experiments, three configurations of the injection slot with $\theta$ equals $0^{\circ}, 30^{\circ}$, and $60^{\circ}$ were used. Similarly, liquid film thickness and film coverage area width were measured. The measured results were shown in Fig. 15. Based on the information from Fig. 15, the following can be identified. (1) Variation of the liquid film velocity with the coolant injection direction is not obvious for the time intervals between probes are almost the same. (2) Increasing the coolant injection direction will cause a larger liquid film width. Meanwhile, the lateral expansion rate of the liquid film layer is also increased. As shown in Fig. 15(d), with $\theta$ increasing from $0^{\circ}$ to $60^{\circ}$, the liquid film coverage area width enlarges approximately 1.2 and 1.5 times. Additionally, the derivative of the liquid film width with respect to the distance to the slot increases nearly 3 times to $1.84 \mathrm{~mm} / \mathrm{mm}$ in the first $10 \mathrm{~mm}$.

\section{Coolant surface tension}

Coolant surface tension is the last influential factor in this series of experiments. Measurement results will be helpful to guide the selection of a coolant for hypersonic liquid film cooling. In our experiments, $0.8 \mathrm{~g}$ of washing powder was added to $500 \mathrm{ml}$ of tap

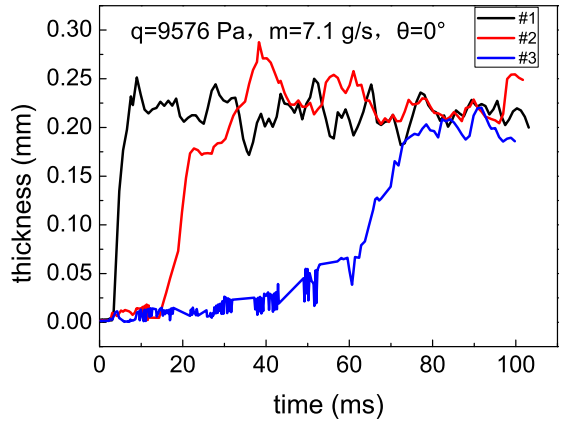

(a)

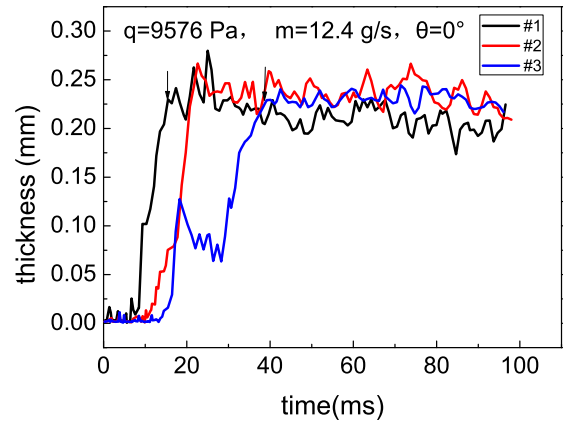

(b)

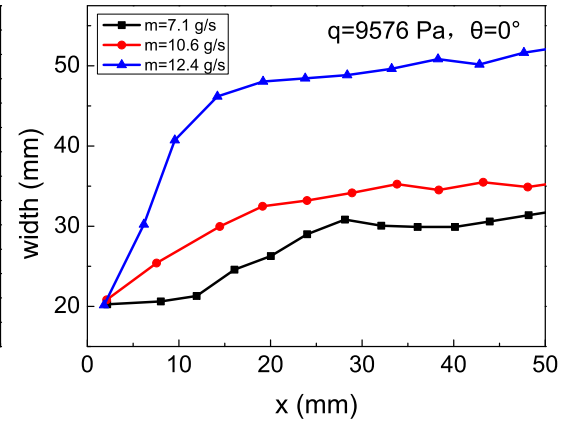

(c)

FIG. 13. Effect of the mass flow rate on the liquid film thickness and coverage area width. (a) $m=7.1 \mathrm{~g} / \mathrm{s},(\mathrm{b}) \mathrm{m}=12.4 \mathrm{~g} / \mathrm{s}$, and (c) coverage area width. 


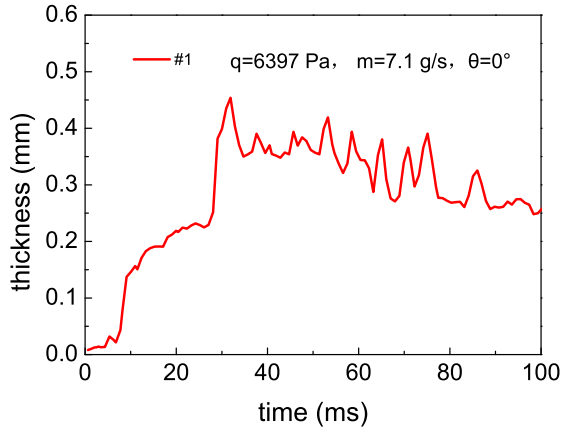

(a)

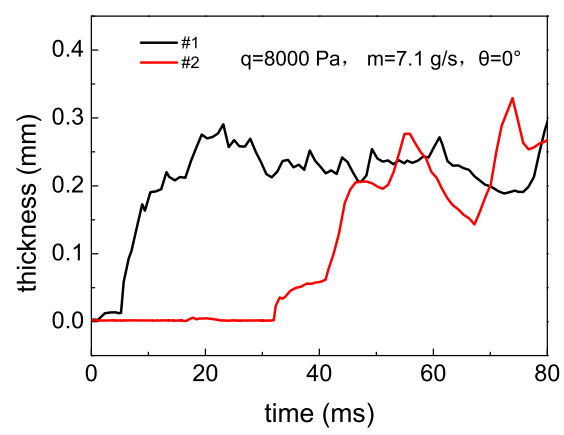

(b)

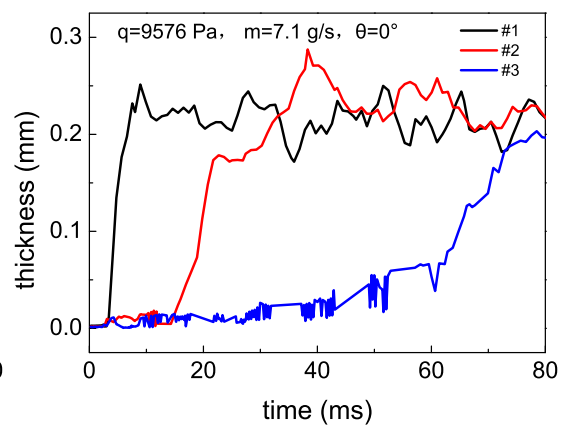

(c)

FIG. 14. Effects of dynamic pressure on the liquid film thickness. (a) $q=6397 \mathrm{~Pa}$, (b) $q=8000 \mathrm{~Pa}$, and (c) $q=9576 \mathrm{~Pa}$.

water. At present, we are not able to accurately measure the surface tension. What is certain is that the surface tension of this mixture is lower than that of pure tap water. Using the mixture as a coolant, small bubbles may be generated in the film, as shown in Fig. 16. Therefore, it is impossible to deduce the film thickness from the voltage output signal. Because conductivity of the film depends on the ratios of tap water, washing powder, and air in the bubble, this value is difficult to determine. However, it is still possible to measure the liquid film leading edge velocity. Voltage outputs of the liquid film thickness measurement system are depicted in Fig. 17. The time interval from probe $\# 1$ to $\# 3$ is $49.5 \mathrm{~ms}$, and the derived average speed is approximately $0.81 \mathrm{~m} / \mathrm{s}$. When no washing powder is added, the corresponding velocity is approximately
$0.80 \mathrm{~m} / \mathrm{s}$. From the results, it can be concluded that surface tension has no effect on the leading edge speed of the liquid film. Similarly, the film coverage area width, as shown in Fig. 18, was extracted and compared with the results conducted with tap water. The coolant surface tension decreased, and the liquid film coverage area width increased. A quantitative analysis of the data in Fig. 18 indicates that the liquid film coverage area width is increased approximately 1.25 times and the width derivative with respect to the distance to slot increased nearly 1.35 times to $4.55 \mathrm{~mm} / \mathrm{mm}$ in the first $10 \mathrm{~mm}$. This means that under the same flow condition and coolant mass flow rate, a coolant with lower surface tension is able to generate a thinner liquid film, which may improve the cooling efficiency.

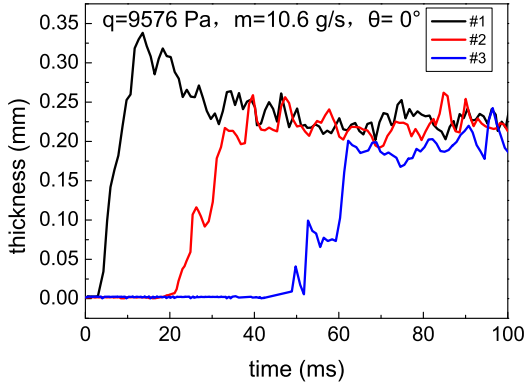

(a)

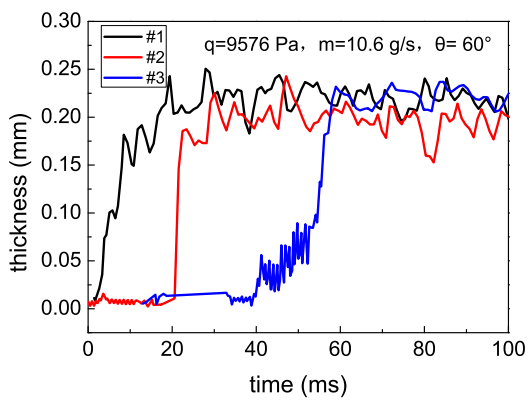

(c)

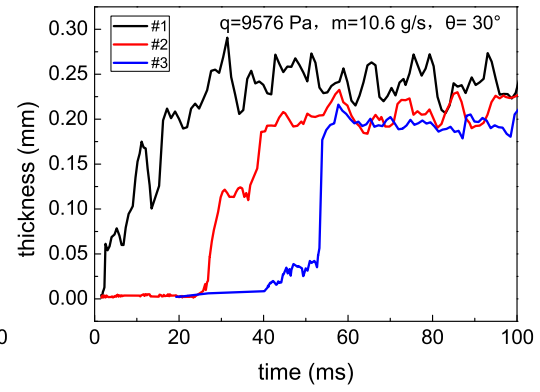

(b)

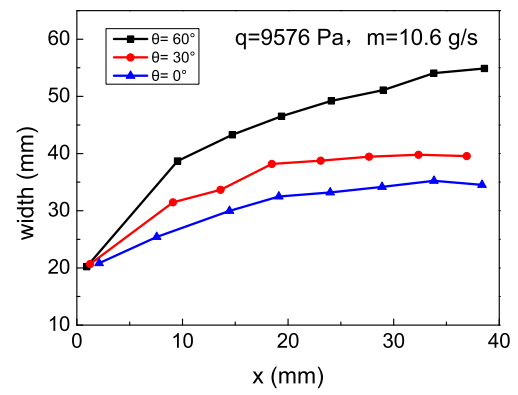

(d)
FIG. 15. Effects of the coolant injection direction on the liquid film thickness and coverage area width. (a) $\theta=0^{\circ}$, (b) $\theta=30^{\circ}$, (c) $\theta=60^{\circ}$, and (d) cover area width. 


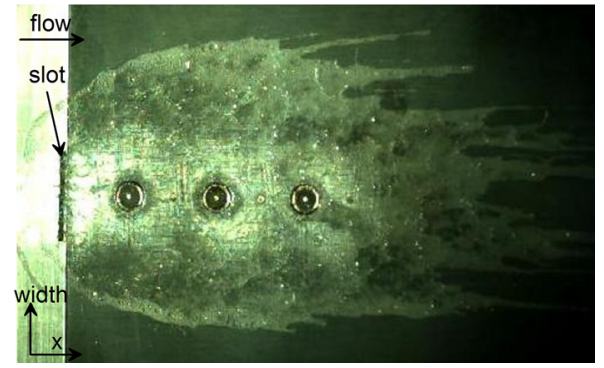

FIG. 16. Liquid film formed on the model surface (with washing powder added to tap water).

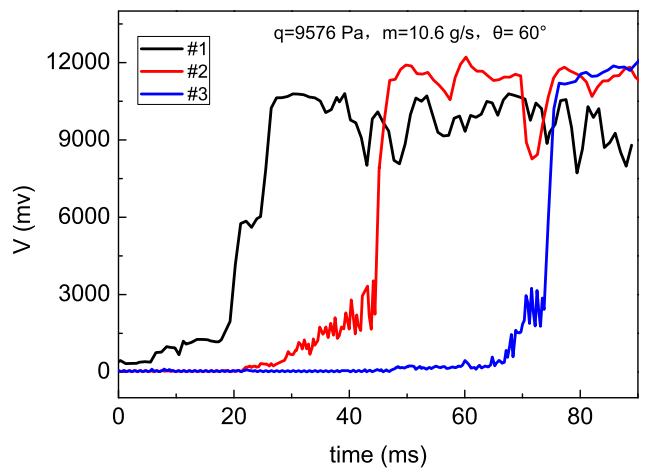

FIG. 17. Voltage outputs of the liquid film thickness measurement system.

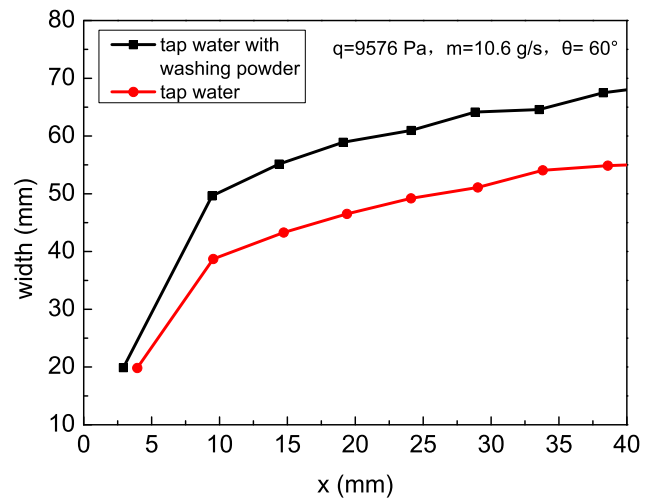

FIG. 18. Effect of coolant surface tension on the liquid film cover area width.

\section{CONCLUSION}

An experimental investigation of hypersonic liquid film cooling of a wedge model under a flow Mach number of 6 was conducted in a detonation tunnel. Based on the measured results, the following conclusions can be drawn:

(1) A liquid film can indeed be formed in hypersonic flow and effectively isolate external high temperature air to reduce surface heating, which means liquid film cooling is a potential active cooling method for the hypersonic thermal protection system.

(2) Coolant injection has negligible effect on the shock wave position, which is very advantageous to maintain aerodynamic performances.

(3) The flow characteristics of the liquid film can be summarized as follows:

(1) The liquid film flow on the wedge surface is a deceleration process dominated by aerodynamic drag.

(2) Surface waves exist in the liquid film and evolve in time and space, which lead to a slight perturbation of the film thickness.

(3) There exists lateral broadening in the liquid film layer. The reason is that the liquid film layer does not match with the flow field boundary condition. The coolant was forced to flow to low-pressure areas, broadening the film width.

(4) Analyses of the influencing factors indicate the following.

(1) Liquid film thickness is mainly determined by the flow dynamic pressure. Higher dynamic pressure will result in a thinner liquid film.

(2) The leading edge velocity of the liquid film depends on the coolant mass flow rate and dynamic pressure. Increasing the coolant mass flow rate and dynamic pressure will increase the film leading edge velocity, which means that it will reduce the start-up time of the hypersonic thermal protection system.

(3) The width of the liquid film coverage area is related to the coolant mass flow rate, injection direction, and surface tension. A wider coverage area can be obtained by increasing the mass flow rate and injection direction or decreasing the coolant surface tension.

\section{ACKNOWLEDGMENTS}

This work was supported by the National Natural Science Foundation of China (Grant Nos. 11602275, 11672312, and 11532014).

\section{REFERENCES}

${ }^{1}$ M. B. Gerdroodbary, M. Imani, and D. Ganji, "Investigation of film cooling on nose cone by a forward facing array of micro-jets in hypersonic flow," Int. Commun. Heat Mass Transfer 64, 42-49 (2015).

${ }^{2}$ D. Glass, "Ceramic matrix composite (CMC) thermal protection systems (TPS) and hot structures for hypersonic vehicles," in 15th AIAA International Space Planes and Hypersonic Systems and Technologies Conference (AIAA, 2008), p. 2682.

${ }^{3}$ Y. Liu and Z. Jiang, "Concept of non-ablative thermal protection system for hypersonic vehicles,” AIAA J. 51, 584-590 (2012).

${ }^{4}$ L. Shen, J. Wang, W. Dong, J. Pu, J. Peng, D. Qu, and L. Chen, “An experimental investigation on transpiration cooling with phase change under supersonic condition,” Appl. Therm. Eng. 105, 549-556 (2016).

${ }^{5}$ S. Gulli, L. Maddalena, and S. Hosder, "Investigation of transpiration cooling effectiveness for air-breathing hypersonic vehicles," in 17th AIAA International Space Planes and Hypersonic Systems and Technologies Conference (AIAA, 2011), p. 2253.

${ }^{6}$ G. Huang, Y. Zhu, Z. Liao, X.-L. Ouyang, and P.-X. Jiang, "Experimental investigation of transpiration cooling with phase change for sintered porous plates," Int. J. Heat Mass Transfer 114, 1201-1213 (2017). 
${ }^{7}$ S. I. Silton and D. B. Goldstein, "Use of an axial nose-tip cavity for delaying ablation onset in hypersonic flow," J. Fluid Mech. 528, 297-321 (2005).

${ }^{8}$ P. Finley, "The flow of a jet from a body opposing a supersonic free stream," J. Fluid Mech. 26, 337-368 (1966).

${ }^{9}$ S. Srinath and K. J. Reddy, "Experimental investigation of the effects of aerospike geometry on aerodynamic drag and heat transfer rates for a blunt body configuration at hypersonic mach numbers," Int. J. Hypersonics 1, 93-114 (2010).

${ }^{10}$ A. Brune, S. Hosder, S. Gulli, and L. Maddalena, "Variable transpiration cooling effectiveness in laminar and turbulent flows for hypersonic vehicles," AIAA J. 53, 176-189 (2014).

${ }^{11} \mathrm{~J}$. Wang, L. Zhao, X. Wang, J. Ma, and J. Lin, "An experimental investigation on transpiration cooling of wedge shaped nose cone with liquid coolant," Int. J. Heat Mass Transfer 75, 442-449 (2014).

${ }^{12}$ M. L. Blosser, R. R. Chen, I. H. Schmidt, J. T. Dorsey, C. C. Poteet, and R. K. Bird, "Advanced metallic thermal protection system development," in The 40th Aerospace Sciences Meeting and Exhibit, 14-17 January 2002, Reno, NV (AIAA, 2002), AIAA Paper 2002-0504.

${ }^{13} \mathrm{~K}$. Heufer and H. Olivier, "Experimental study of active cooling in 8 laminar hypersonic flows," in RESPACE-Key Technologies for Reusable Space Systems, edited by A. Gülhan (Springer, Berlin, Heidelberg, 2008), pp. 132-150.

${ }^{14}$ A. M. Cary and J. N. Hefner, "Film-cooling effectiveness and skin friction in hypersonic turbulent flow," AIAA J. 10, 1188-1193 (1972).
${ }^{15}$ N. Sahoo, V. Kulkarni, S. Saravanan, G. Jagadeesh, and K. Reddy, "Film cooling effectiveness on a large angle blunt cone flying at hypersonic speed," Phys. Fluids 17, 036102 (2005).

${ }^{16} \mathrm{R}$. Sriram and G. Jagadeesh, "Film cooling at hypersonic Mach numbers using forward facing array of micro-jets," Int. J. Heat Mass Transfer 52, 3654-3664 (2009).

${ }^{17}$ A. V. Foreest, M. Sippel, A. Gülhan, B. Esser, B. C. Ambrosius, and K. Sudmeijer, "Transpiration cooling using liquid water," J. Thermophys. Heat Transfer 23, 693-702 (2009).

${ }^{18}$ C. B. Tibiriçá, F. J. do Nascimento, and G. Ribatski, "Film thickness measurement techniques applied to micro-scale two-phase flow systems," Exp. Therm. Fluid Sci. 34, 463-473 (2010).

${ }^{19}$ N. Jin, Z. Xin, J. Wang, Z. Wang, X. Jia, and W. Chen, "Design and geometry optimization of a conductivity probe with a vertical multiple electrode array for measuring volume fraction and axial velocity of two-phase flow," Meas. Sci. Technol. 19, 045403 (2008).

${ }^{20} \mathrm{~J}$. D. Anderson, Jr., Hypersonic and High-Temperature Gas Dynamics (American Institute of Aeronautics and Astronautics, 2006).

${ }^{21}$ Y. Zhou, H. Wu, Y. Li, and Y. Cai, "Two-dimensional film cooling over a flat plate in hypersonic flow," Propul. Power Res. 7, 205-217 (2018).

${ }^{22}$ D. Bountin, A. Maslov, and Y. Gromyko, "Analysis of disturbances in a hypersonic boundary layer on a cone with heating/cooling of the nose tip," Phys. Fluids 30, 054103 (2018). 